\title{
Práticas discursivas multimodais no WhatsApp: uma análise verbo-visual
}

Renata da Fonte* Roberta Caiado**

\section{Resumo}

Neste artigo, discutimos práticas discursivas multimodais encontradas no aplicativo WhatsApp com o propósito de refletir a relação entre o texto verbal e a imagem. Respaldamo-nos na perspectiva da multimodalidade, principalmente nos fundamentos da Semiótica Social, fundamentando-nos nos trabalhos de Kress (1998) e Kress; Leeuwen (1996, 2011) para análise do discurso multimodal e do papel da imagem utilizada nesse meio digital. Os enunciados multimodais presentes nas práticas discursivas do WhatsApp revelam a imagem como modo semiótico privilegiado para a construção de sentido na tessitura discursiva na tela de dispositivos móveis - smartphones.

Palavras-chave: Multimodalidade. Semiótica Social. Práticas discursivas. WhatsApp.

\section{Introdução}

Este artigo propõe discutir os aspectos multimodais encontrados em práticas discursivas presentes em dispositivos móveis - smartphones - mais especificamente no aplicativo WhatsApp, de forma a refletir sobre a relação entre texto verbal e visual e sobre os papéis da imagem na constituição multimodal do discurso na tela. Para isso, as reflexões serão respaldadas na perspectiva da semiótica social, proposta por Kress e Van Leeween (2001), na qual o discurso é multimodal, uma vez que é constituído por modos semióticos, que se articulam na construção de sentido da teia discursiva.

* Doutora em Linguística. Professora e pesquisadora do Programa de Pós-Graduação da Universidade Católica de Pernambuco. Área de atuação: Linguagem e Multimodalidade. E-mail: renatafffonte@gmail.com

** Doutora em Educação. Professora pesquisadora da Universidade Católica de Pernambuco. Área de atuação: Linguagem e Tecnologias. E-mail: r.caiado@globo.com

Data de submissão: jul. 2014 - Data de aceite: ago. 2014 http://dx.doi.org/10.5335/rdes.v10i2.4147 
$\mathrm{Na}$ contemporaneidade, o avanço tecnológico da mídia digital, em especial das tecnologias móveis, promove o surgimento de diversos aplicativos e novos acessórios que possibilitam a leitura e a produção discursiva na tela. Exemplo dessas tecnologias móveis são os smartphones, que contribuem para o surgimento de novas práticas discursivas mediadas por textos verbais e visuais.

Logo, o discurso constituído com o auxílio das tecnologias digitais da informação e comunicação é, em sua essência, multimodal. O bate papo no WhatsApp é multimodal, pois os recursos disponibilizados no aplicativo possibilitam mesclar diferentes modos semióticos, como som, imagem, vídeo, texto verbal na tela.

O WhatsApp Messenger é um aplicativo que permite trocar mensagens pelo celular/smartphone. Está disponível para telefones iPhone, BlachBerry, Android, Windows Phone e Nokia com acesso à internet (3G ou WI-FI, quando disponível). O WhatsApp possibilita enviar mensagens escritas, de áudio e de vídeo e imagens. O aplicativo foi criado em 2009 pelo norte-americano Brian Acton e pelo ucraniano Jan Koum, que foram funcionários do Yahoo. A ideia de criar esse aplicativo, que possibilita a troca de mensagens, foi de Jan Koum e surgiu no momento em que a academia que frequentava proibiu o uso de celulares. As ligações perdidas, enquanto praticava esportes, o incomodavam e o mobilizaram a pensar em uma alternativa para essa questão, daí a ideia de criar o WhatsApp. ${ }^{1}$
Segundo Ferro (2014), esse aplicativo é considerado um dos projetos de maior sucesso no meio digital, pois conta com elevada adesão de usuários de dispositivos móveis. Nos primeiros quatro anos de vigência, o crescimento do WhatsApp é superior ao do Facebook.

Podemos encontrar na interação via WhatsApp diversos gêneros discursivos, que variam quanto ao estilo, ao formato e ao conteúdo. Esses gêneros podem permear práticas discursivas formais ou informais. Essas práticas multimodais integram palavras, sons, imagens e movimentos, sincronicamente, em um meio caracterizado por noções de multilinearidade e exigem dos sujeitos dialógicos "atitudes ativamente responsivas", conforme propõe a perspectiva dialógica bakthiniana.

Discutir a multimodalidade atrelada à tecnologia digital móvel e refletir sobre a inter-relação entre texto verbal e imagem em práticas discursivas ocorridas no aplicativo WhatsApp torna-se necessário frente aos desafios impostos pela cultura digital, que envolvem práticas diferenciadas de leitura e escrita na tela.

\section{A multimodalidade em dispositivos digitais móveis}

As novas tecnologias digitais da informação e comunicação permitem mesclar diferentes modos de representação: a imagem pode ser combinada ao texto escrito, o som e o movimento adicionado à imagem (KRESS, 1998). Tais tecnologias 
são capazes de reunir simultaneamente múltiplas semioses (texto, som e imagem) em gêneros discursivos no meio digital (MARCUSCHI, 2010), favorecendo a bricolagem de várias linguagens amalgamadas em um mesmo suporte (XAVIER, 2009) e as diversas possibilidades de significação do texto eletrônico nas interações on-line (ROJO, 2009).

Kress (1998) ressalta que o discurso sempre teve natureza multissemiótica, apesar disso, privilegiava-se o papel do texto escrito, deixando-se de considerar o potencial representacional e comunicacional do texto visual. Segundo o autor, os aspectos visuais nas tecnologias contemporâneas, como no computador, podem estar relacionados aos tipos e tamanhos de fontes e layout, que configuram o texto.

Conceber o discurso como constituição multimodal é essencial para compreender os vários modos semióticos que estão integrados nas práticas discursivas presentes no meio digital, pois a forma como a linguagem verbal relaciona-se à visual contribui para a construção de sentido na interação dialógica.

A multimodalidade no discurso implica o uso de vários modos semióticos. A maneira como esses modos são combinados pode reforçar a mesma ideia, desempenhar papéis complementares ou hierárquicos, nos quais um determinado modo semiótico predomina em relação ao outro (KRESS; LEEUWEN, 2011). Nesse caso, o conteúdo do discurso pode ser expresso, principalmente, pelo texto verbal ou pela imagem. $\mathrm{O}$ aplicativo para dispositivos móveis WhatsApp favorece a mescla de diversos modos semióticos, sejam de natureza verbal, por meio de sons ou da escrita, sejam de constituição visual, como é o caso da imagem.

Para o estudo das imagens, Kress e Leeuwen (1996) propõem a Gramática do Design Visual, advogando que a linguagem visual possui uma sintaxe própria, uma vez que seus elementos estão organizados entre si para expressar significados coerentes.

A seleção de determinado modo semiótico depende do objetivo do sujeito na prática discursiva e indica o conteúdo do que pretende expressar. Segundo Barros e Meira (2010), na perspectiva da Semiótica Social, o autor e o leitor selecionam um modo semiótico para destacá-lo em um momento específico da interação.

A respeito da relação da imagem com texto escrito, Santanella e Nöth (2008 [1997], p. 54) retomam considerações de Barthes (1964) e de Kalverkämper (1993). Os autores ressaltam o questionamento de Barthes (1964, p. 38):

Será que a imagem é simplesmente uma duplicata de certas informações que um texto contém, e portanto, um fenômeno de redundância, ou será que o texto acrescenta novas informações à imagem?

Partindo desse questionamento, Santanella e Nöth (1997) afirmam que a relação imagem-texto ocorre em um contínuo que vai da redundância à informatividade. Com base nas observações de Kalverkämper (1993), nesse contínuo, há três formas distintas de relação da imagem com o texto. A imagem pode 
ser inferior ao texto, sendo, portanto, redundante, caso em que podemos citar as ilustrações cuja presença da imagem não é essencial para a compreensão do texto, logo se excluídas do texto não comprometem sua compreensão; a imagem pode ser superior ao texto quando é mais informativa em relação a ele, situando-se, portanto, na escala da informatividade. Neste tipo de composição textual "sem a imagem, uma concepção do objeto é muito difícil de ser obtida" (SANTANELLA e NÖTH, p. 56-57); ou a imagem pode ser equivalente à palavra, quando a imagem é integrada ao texto, tendo a mesma importância, sugerindo que a relação entre imagem e texto encontra-se no meio do contínuo, entre a redundância e a informatividade, essa relação de equivalência entre texto e imagem.

Martinec e Salway (2005) mencionam que o status de equivalência ou igualdade entre imagem e texto pode caracterizar uma relação de independência ou de complementariedade.

Segundo os autores, imagem e texto são independentes e de igual status quando se combinam, mas um não modifica $o$ outro. Quando ambos se modificam, seu status é considerado complementar.

No status de igualdade, seja independente ou complementar, a imagem inteira relaciona-se a um texto inteiro. Quando a imagem relaciona-se a apenas uma parte do texto ou quando o texto está relacionado à parte da imagem, o status é de subordinação, caracterizando uma relação desigual (MARTINEC; SALWAY, 2005).
Martinec e Salway (2005) sintetizam os diferentes status da relação entre imagem e texto por meio do diagrama a seguir:

Figura 1: Status do sistema de relação imagem-texto

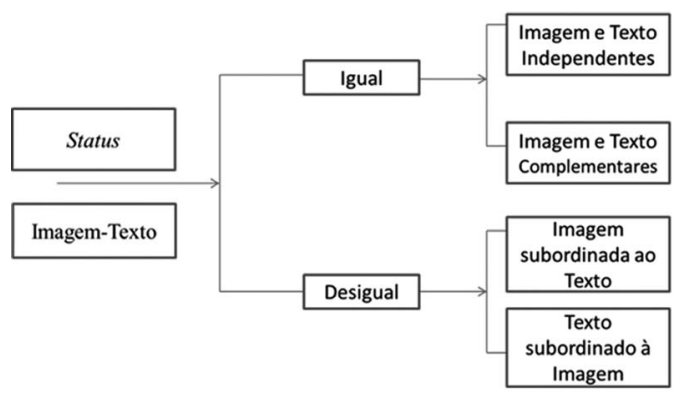

Fonte: Martinec; Salway, 2005, p. 349 (tradução nossa).

Ao refletir sobre as relações entre imagem e texto, Barthes (1977) propõe duas formas principais de inter-relação: ancoragem e relay. Na primeira, o texto direciona o leitor para o significado da imagem, ajudando-o a identificar os elementos dela. $\mathrm{O}$ texto faz referência à imagem. Nessa forma de relação, o texto tem a função de elucidar parte da mensagem icônica. A relação de ancoragem pode ser encontrada em fotografias de imprensa e anúncios. Já na inter-relação denominada relay, texto e imagem são complementares. As palavras e as imagens são fragmentos de um sintagma mais geral, como acontece nos desenhos animados e nas histórias em quadrinhos.

A relação imagem-texto de ancoragem nos faz pensar no texto que funciona como legenda da imagem, guiando o leitor para o sentido dela. Logo, o texto serve de base para a leitura da imagem. 
Já na relação entre imagem e texto conhecida como relay, o leitor necessita observar a imagem e o texto para captar o sentido do discurso multimodal, lembrando o status de igualdade entre imagem-texto, defendido por Martinec e Salway (2005).

Segundo Kress e Van Leeuwen (1996), a imagem, como parte integrante do texto escrito, contribui para o observador compreender a semiótica da composição textual e a ideologia do produtor do texto.

As tecnologias digitais móveis favorecem a construção de textos multissemióticos sem que para isso seus usuários necessitem de expertise, porém, ser letrado digital contribui para integrar diferentes modos semióticos disponíveis no meio digital.

Xavier (2005, p. 135) afirma que:

Ser letrado digital pressupõe assumir mudanças nos modos de ler e escrever os códigos e sinais verbais e não-verbais, como imagens e desenhos, se compararmos às formas de leitura e escrita feitas no livro, até porque o suporte sobre o qual estão os textos digitais é a tela, também digital.

As práticas discursivas no WhatsApp são permeadas por discursos multimodais e exigem sujeitos autônomos, ativos, intencionais, na medida em que deverão selecionar os modos semióticos para a constituição da tessitura discursiva.

No próximo tópico, refletiremos sobre a maneira que os sujeitos relacionam texto verbal/escrito e imagem no aplicativo WhatsApp, a partir da análise de fragmentos de práticas discursivas ocorridas nesse aplicativo.

\section{Procedimentos metodológicos para a análise verbo-visual de discursos multimodais no WhatsApp}

A realização desta pesquisa envolveu uma análise verbo-visual de discursos multimodais no aplicativo WhatsApp. Para essa análise, selecionamos três fragmentos de práticas discursivas de diferentes usuários desse aplicativo.

O WhatsApp contribui para a constituição do discurso multimodal, no qual há possibilidade de mesclar palavras e emoji, anteriormente denominado emoticons, que tem origem japonesa. Shigetaka Kurita foi o criador dos emoji orientais. A ideia de sua criação surgiu nos anos de 1990, diante da necessidade de ferramentas e técnicas rápidas de comunicação, principalmente, do público adolescente japonês. Inicialmente, $\mathrm{Ku}$ rita e uma equipe de designers criaram 176 carinhas, capazes de expressar variadas emoções. Mais tarde, essa ideia foi difundida por outras empresas, que elaboraram outros conjuntos de emoji. ${ }^{2}$ Os ícones passaram a ser usados no texto digital, elegendo desenhos com a função de expressar ideias específicas ou um estado de humor. ${ }^{3}$

No WhatsApp há diversos ícones ou emoji, que incluem carinhas com expressões faciais diferenciadas, gestos manuais, símbolos relacionados às profissões, e que expressam sentimentos, pessoas, 
relógio com a marcação da hora, objetos variados, animais, números, frutas, partes do corpo, placas, entre outros. Abaixo apresentamos alguns exemplos desses emoji disponíveis no aplicativo.

Figura 2 - Exemplos de Emojipara smartphones

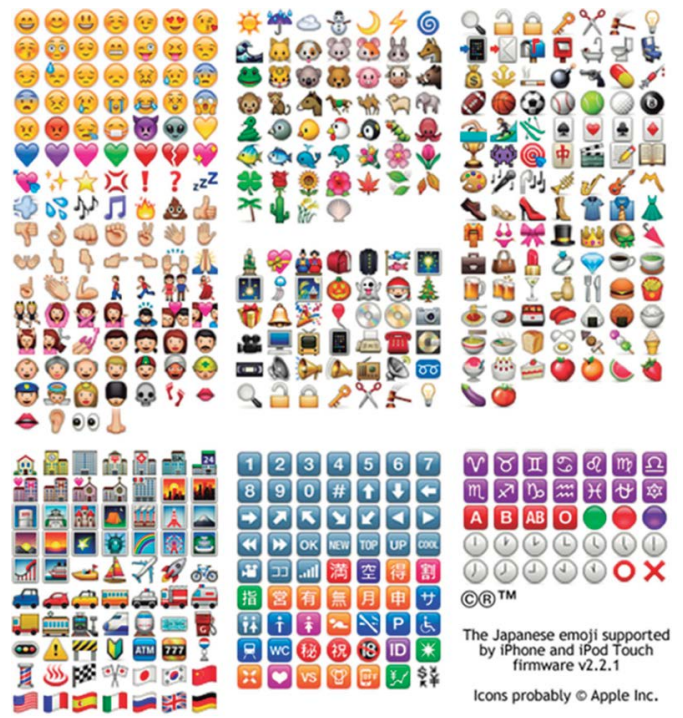

Fonte: Dispónível em: <http://inner.geek.nz/archives/2009/ 02/06/the-truth-about-iphone-emoji/>.

Analisaremos, a seguir, qualitativamente, três fragmentos de práticas discursivas extraídas do aplicativo What$s A p p$, na tentativa de refletir, a partir da classificação proposta por Martinec e Salway (2005), os usos que os sujeitos fazem dos aspectos multimodais na relação entre texto verbal e visual e sobre os papéis da imagem na constituição multimodal do discurso na tela.

\section{Análise e discussão dos discursos multimodais no WhatsApp}

Ao analisar as práticas discursivas no aplicativo WhatsApp, realçaremos a relação entre palavra e imagem, e o papel desta última em três contextos de interação distintos.

CONTEXTO 1: WhatsApp de uma família. Participam deste grupo 10 (dez) pessoas.

PERFIL DOS SUJEITOS - IDADE FORMAÇÃO - TEMPO QUE USA O APLICATIVO: No contexto abaixo 02 (dois) sujeitos interagem. Com idades próximas: 62 anos, 60 anos; ambos os sujeitos utilizam o aplicativo há mais de dois anos.

Figura 3 - Prática discursiva I

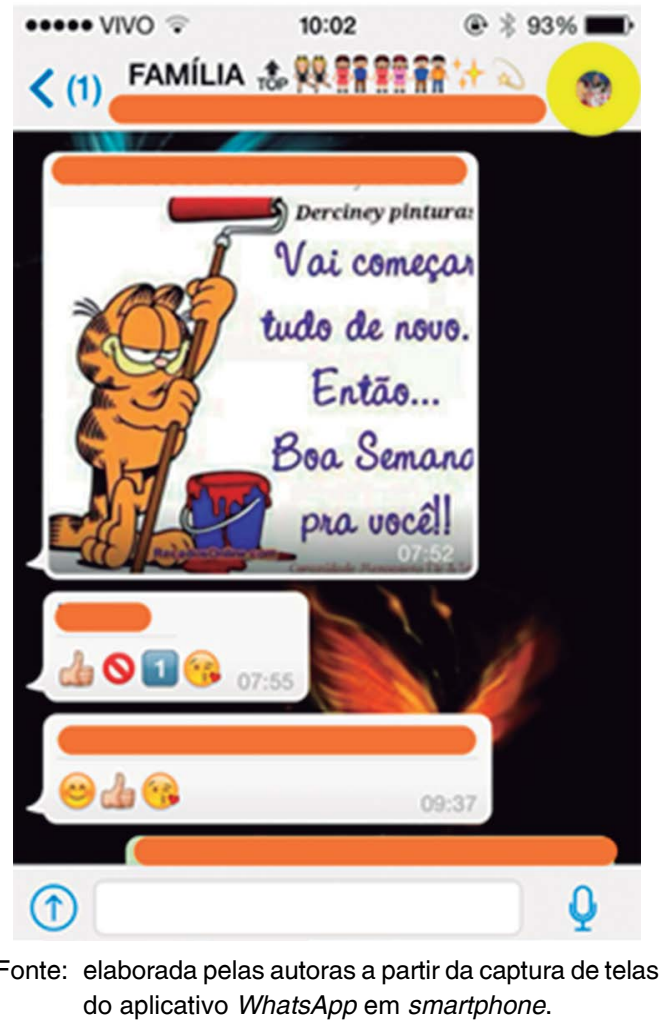


Na prática discursiva acima, participaram dois sujeitos pertencentes ao grupo familiar, um sujeito de 62 anos e outro sujeito de 60 anos. $O$ contexto temático envolvido foi o feriado do dia do trabalhador, que é comemorado no dia primeiro de maio.

Para iniciar o bate papo no aplicativo, o sujeito 1 utiliza um recurso do aplicativo WhatsApp, que foi o de inserir um cartaz, que continha uma mensagem verbal caracterizada pelo texto escrito: "Vai começar tudo de novo. Então... Boa Semana pra você!!” acompanhada da imagem ilustrativa do personagem Garfield.

Ao ocupar o turno discursivo, o sujeito 2 interage utilizando, apenas, emoji, inserindo quatro deles em sequência temporal na sua enunciação digital. $\mathrm{O}$ primeiro emoji utilizado pelo sujeito 2 representa o gesto manual que expõe o dedo polegar para cima, sinalizando o gesto emblemático de "positivo". No contexto dessa interação, esse tipo de imagem pode ter sido utilizada como forma de compreensão acerca do que foi dito por Garfield ou como introdução da sua resposta que tinha a intenção de relembrar ao sujeito 1 que o próximo feriado (parada obrigatória) estava próximo. Os gestos emblemáticos são construídos socialmente e determinados culturalmente e podem ser realizados na presença ou na ausência da fala (MCNEILL, 2000). $\mathrm{Na}$ interação dialógica do fragmento I, o ícone que representa o gesto emblemático foi apresentado na ausência do texto escrito.
Na sequência, o sujeito 2 expõe o segundo ícone, que é de uma placa de trânsito, com o significado de "parada obrigatória" e depois introduz o ícone do número 1, que representa, pela imagem, o dia de um calendário. Esse ícone indica o dia que ocorrerá a "parada obrigatória", dia primeiro de maio, dia do trabalhador. Para encerrar seu turno, o sujeito 1 "sorri", por meio da carinha que representa sorriso, acrescenta outro ícone de "positivo", inferimos que concordando com a afirmação do sujeito $2 \mathrm{e}$ sentindo-se satisfeito, e introduz o emoji da carinha que solta um beijo de coração, como forma de despedida. As imagens substituíram o texto verbal, garantindo a construção coesa, coerente e com sentido do texto visual.

O sujeito 1, quando volta a ocupar o turno discursivo, após o primeiro cartaz enviado, também faz uso, apenas, da imagem - de emoji - na construção do seu discurso. Incialmente, introduz uma carinha com sorriso, expressando satisfação com o feriado. Essa ideia de contentamento também é reforçada pelo gesto emblemático que sinaliza legal. Por fim, o sujeito encerra a interação dialógica com a carinha, que solta um beijo, retribuindo o mesmo ato de seu interlocutor a partir da mesma imagem.

Nesse fragmento, os emoji substituem o texto verbal, sendo realçados na constituição dos discursos dos sujeitos, que são formados apenas pelas imagens que significam e contextualizam a prática discursiva. Logo, o discurso na tela, na Prática Discursiva I é de natureza essen- 
cialmente visual. Consideramos que as imagens possuem status de independência absoluta, uma vez, que foram usadas na interação sem a presença do texto verbal e com coerência semântica, situando-se no contínuo da informatividade.

Esse tipo de status da imagem tem sido encontrado em outras práticas discursivas de sujeitos considerados letrados digitais, que utilizam o aplicativo WhatsApp.

Em um contexto interativo diferente, observamos o uso de texto visual e de texto verbal na constituição do discurso dos sujeitos.

CONTEXTO 2: WhatsApp de um casal. PERFIL DOS SUJEITOS - IDADE FORMAÇÃO - TEMPO QUE USA O APLICATIVO: Os 02 (dois) sujeitos possuem ensino superior completo e tem 51 anos; utilizam o aplicativo há três anos.

Figura 4 - Prática discursiva II

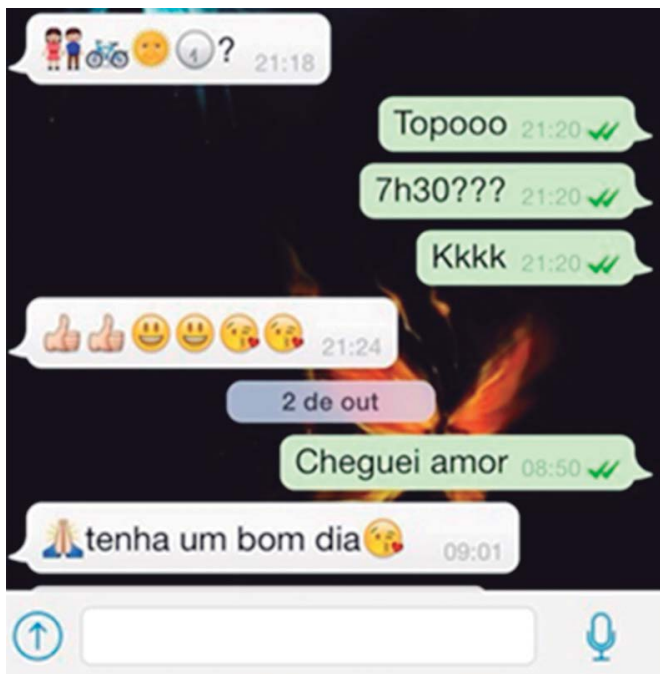

Fonte: elaborada pelas autoras a partir da captura de telas do aplicativo WhatsApp em smartphone.
A prática discursiva II mostra dois contextos de interações distintos: convite e comunicado de chegada a um determinado destino.

No primeiro contexto, o sujeito 1 inicia a interação dialógica na tela com o intuito de convidar o sujeito 2 para andar de bicicleta. Para isso, o sujeito 1 combina quatro emoji (figura de casal + bicicleta + sol + relógio, que marca o horário das 7h30) seguido do ponto de interrogação; inferimos que o significado desse texto visual seja: "Vamos andar de bicicleta às 7 h30 ?". No contexto dialógico, as imagens articulam-se de forma coesa e coerente na constituição do discurso do sujeito 1. Logo, dispensam palavras para seu entendimento, ocupando o status de independência absoluta e situando-se na escala da informatividade.

A compreensão do sujeito 2 é clara quando esse ocupa o turno discursivo, enfaticamente, por meio do texto verbal "Topooo" ao aceitar o convite do sujeito 1 expresso no discurso de natureza imagética. Em seguida, confirma o horário da atividade física por meio do questionamento: "7h30???" e encerra seu turno discursivo com as letras "Kkkk", que significam gargalhadas no meio digital, representando sua sonoridade em interações face a face e, também, o fato de o sujeito 1 ter conhecimento de que o sujeito 2 não gostava de acordar cedo para prática de esportes. No contexto dialógico, os textos verbais representam o status de independência absoluta, sendo informativos. 
Diferentemente do discurso do sujeito 1 , que teve constituição visual, o discurso do sujeito 2 foi de natureza verbal de forma a aproximar a interação na tela da interação face a face. No discurso desse sujeito, observamos marcas significativas como o alongamento da palavra "Topo", que foi grafada "Topooo". Essa estratégia de triplicar a letra modifica o layout do texto escrito tradicional e tem a função de substituir o alongamento da duração da palavra falada nas interações face a face e pode ter sido utilizada para enfatizar seu aceite e expressar grande interesse pelo convite.

Diante do aceite do sujeito 2, o sujeito 1 usa dois ícones que representam o gesto emblemático de legal; o primeiro pode ter significado sua satisfação do aceite do convite e o segundo pode ter sido usado para confirmar o horário do passeio de bicicleta. Após o uso desses ícones emblemáticos, seu discurso apresenta dois emoji da carinha sorridente, demostrando seu estado de alegria e para fechar seu turno expõe duas carinhas que soltam um beijo de coração, caracterizando um contexto de despedida com afeto. $\mathrm{O}$ discurso do sujeito 1 foi de natureza visual com status de independência absoluta em relação ao texto verbal ausente. Logo, a imagem está situada no contínuo da informatividade.

No segundo contexto, o sujeito 2 ocupa o turno discursivo para comunicar sua chegada. Para isso, usou apenas o texto verbal "Cheguei amor". O sujeito 1 insere-se na interação por meio do discurso multimodal ao integrar imagens e texto verbal em seu enunciado digital. Introduz seu turno com um ícone de contexto religioso - duas mãos unidas em sinal de oração/agradecimento. Nesse contexto dialógico, essa imagem poderia significar a expressão "graças a Deus". Em seguida, deseja para o sujeito 2 um bom dia por meio do texto verbal. No fecho do seu enunciado, volta a usar imagem representada pelo emoji da carinha que manda "beijo de coração". As imagens e o texto verbal apresentam dados novos, ou seja, expressam diferentes significados, que dão continuidade ao discurso de forma coesa e coerente. Podemos pensar numa relação entre imagem-texto de complementariedade do discurso multimodal.

Um terceiro tipo de inter-relação entre imagem e texto verbal no aplicativo WhatsApp pode ser evidenciado na interação dialógica abaixo.

CONTEXTO 3: WhatsApp de uma família. Participam deste grupo 10 (dez) pessoas. PERFIL DOS SUJEITOS - IDADE FORMAÇÃO - TEMPO QUE USA O APLICATIVO: No contexto abaixo 03 (três) sujeitos interagem. Todos possuem ensino superior completo e têm respectivamente: 62 anos, 60 anos e 49 anos; os sujeitos utilizam o aplicativo há mais de dois anos. 
Figura 5: Prática discursiva III

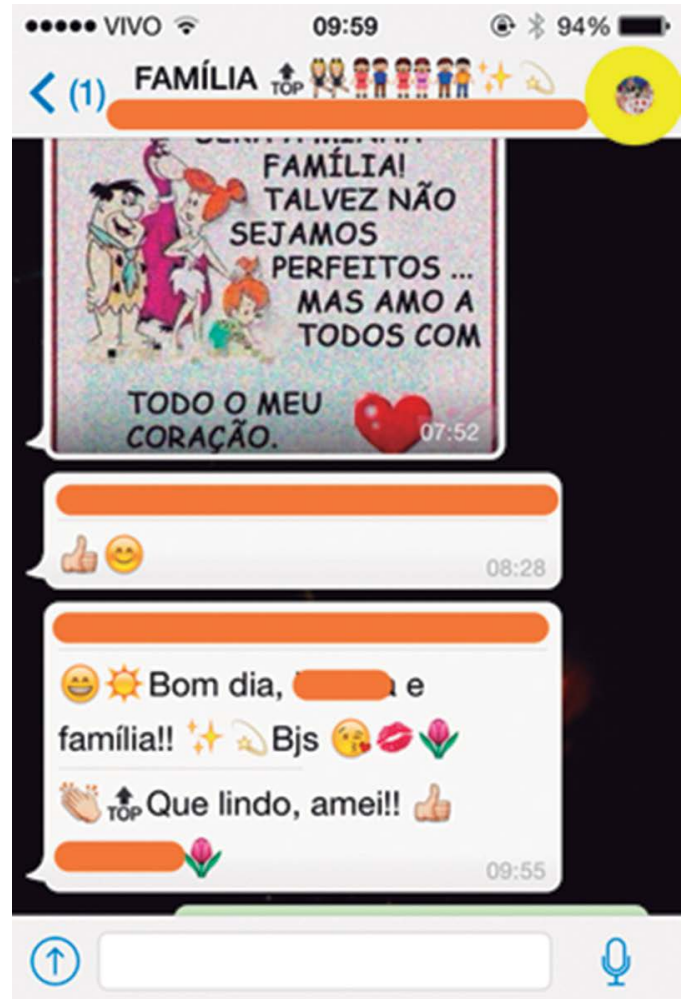

Fonte: elaborada pelas autoras a partir da captura de telas do aplicativo WhatsApp em smartphone.

Ao iniciar a interação dialógica, o sujeito 1 insere um cartaz constituído de texto multimodal, no qual há a imagem da família dos Flintstones do lado esquerdo acompanhada de uma mensagem verbal sobre "família". Nesse caso, com base na classificação de Kalverkämper (1993), a imagem é inferior ao texto, sendo redundante, pois sua presença não é primordial para construção de sentido do texto, seu papel é de ilustração. Neste exemplo, a imagem teve o papel de sintetizar o texto verbal, ou melhor, de realçar a palavra-chave, a temática do cartaz. Conforme considerações de Martinec e Salway (2005), a imagem relaciona-se à palavra "família" do texto verbal, indicando uma relação imagem-texto desigual, de subordinação. Esse mesmo status pode ser observado no final do cartaz. Segundo Kress e Leeuwen, (2011 [2001]), a imagem da "família" e a do "coração" têm o papel de enfatizar as palavras escritas.

O sujeito 2 assume o turno discursivo usando apenas emoji, ao incorporar no seu discurso o ícone emblemático de legal, revelando a aprovação da mensagem, e na sequência, a carinha sorrindo, mostrando estado de satisfação.

Já o sujeito 3 mesclou em seu discurso imagens e texto verbal. Sua entrada no turno discursivo inicia com a exposição da carinha com sorriso, sinalizando sua satisfação com a mensagem sobre a família. Em seguida, incorpora em seu enunciado a imagem do sol que antecipa e contextualiza o texto verbal posterior, que expressa "bom dia". Nesse momento, a inter-relação entre imagem e texto verbal é de ancoragem, pois o texto verbal favorece a compreensão da imagem expressa. De outro modo, a compreensão do texto verbal não depende da presença da imagem, logo é inferior ao texto, funcionando como ilustração. Dando continuidade ao seu turno, o sujeito 3 expõe, em sequência, vários outros emoji. Ressaltamos que a presença da mesclagem entre texto verbal e visual foi evidenciada no contexto de fechamento do turno, na despedida, quando grafa "Bjs" seguido de dois emo- 
$j i$, distintos, de beijo. A linguagem visual expressa pelos emoji teve o papel de reforçar a palavra escrita. Nesse caso, imagem e texto verbal são equivalentes no significado, apresentam, segundo Martinec e Salway (2005), status igual e independente.
Nas práticas discursivas analisadas, no aplicativo WhatsApp, os sujeitos dialógicos inter-relacionaram texto verbal/ escrito e imagem de formas diversas. Logo, esses modos semióticos apresentaram status diferenciados: superior, igual ou inferior, conforme representamos no diagrama abaixo.

Figura 6 - Status do sistema de relação Imagem-Texto no WhatsApp

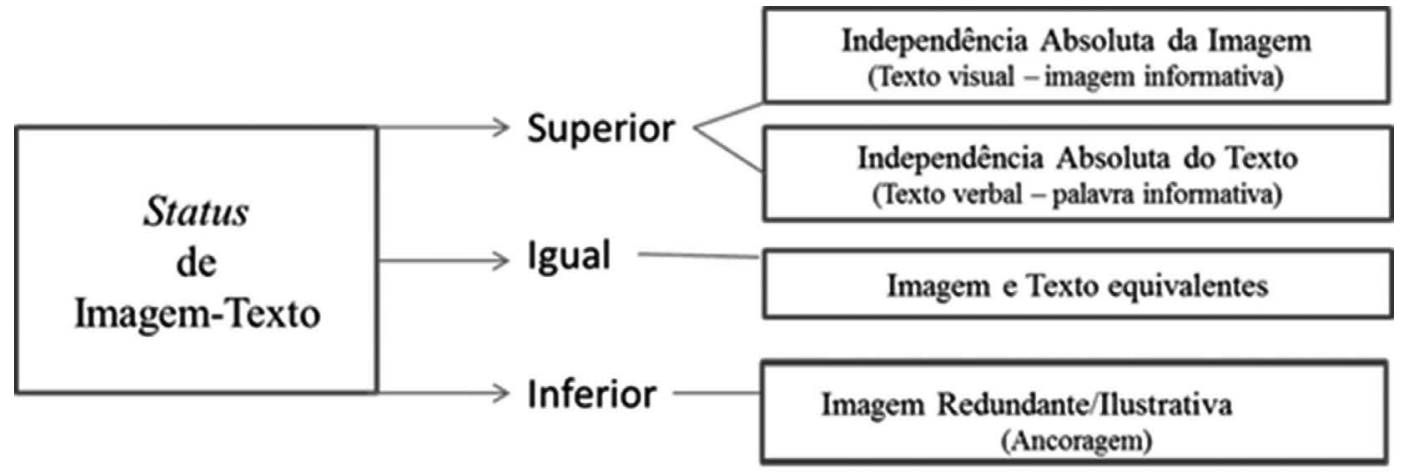

Fonte: elaborada pelas autoras.

\section{Considerações finais}

No aplicativo WhatsApp há uma predominância do status de independência absoluta da imagem em relação ao texto verbal nos sujeitos analisados, pois ela exerce papel relevante para a construção do enunciado digital com caráter informativo no contexto dialógico pesquisado. $\mathrm{O}$ processo de letramento digital dos sujeitos participantes da pesquisa contribuiu para este uso, garantindo rapidez e expressão diferenciada de ideias complexas.

Em relação aos papéis da imagem nas práticas discursivas analisadas, nesse aplicativo, destacam-se: i) Imagem substituta do texto verbal;

ii) Imagem que enfatiza o sentido do texto verbal;

iii) Imagem que antecipa o texto verbal;

iv) Imagem que ilustra o texto verbal;

v) Imagem que sintetiza o texto verbal.

No WhatsApp, as práticas discursivas multimodais são favorecidas, tendo em vista os recursos disponíveis nesse aplicativo, o contexto e o propósito da interação, assim como o grau de intimidade dos sujeitos e o tempo de uso do WhatsApp. 


\section{Multimodal discursive practices in WhatsApp: verb-visual analysis}

\section{Abstract}

In this article, we discuss multimodal discursive practices found in WhatsApp application in order to reflect the relationship between the verbal text and the image. We endorsed in the perspective of multimodality, especially in the fundamentals of Social Semiotics, grounding in the work of Kress (1998); Kress and Leeuwen $(1996,2011)$ for analysis of multimodal discourse and the role of the image used in this digital medium. Multimodal utterances present in the discursive practices of WhatsApp reveal the image as a privileged semiotic mode for the construction of meaning in the discursive fabric of the mobile screen devices - smartphones.

Keywords: Multimodality. Social Semiotics. Discursive practices. WhatsApp.

\section{Notas}

1 Disponível em: <http://www.tecmundo.com. br/facebook/51567-tudo-sobre-a-compra-do-whatsapp-pelo-facebook-infografico-.htm>. Acesso em: 6 jun. 2014.

2 Disponível em: <http://www.tecmundo.com.br/ telecomunicacoes/38024-emoji-como-os-emoticons-inauguraram-uma-nova-linguagem-digital.htm>. Acesso em: 7 jun. 2014.

3 Disponível em: <http://www.jb.com.br/ciencia-e-tecnologia/noticias/2011/12/07/conheca-os-emoji-emoticons-elaborados-do-iphone-4s. htm>. Acesso em: 7 jun. 2014.

\section{Referências}

BARTHES, R. Rhétorique de l'image. Communications. Paris: Seuil. n. 4, p. 40-51, 1964.

The death of the author. In:

Image, music, text. London: Fontana Press, 1977, p. 142-148.

FERRO, B. $O$ WhatsApp mudou a forma de se comunicar pelo celular. São José do Rio Preto, 26 de fevereiro de 2014. In: Diário da região. Disponível em: <http://www.diarioweb.com.br/ novoportal/noticias/tecnologia/172799,,O+Wh atsApp+mudou+a+forma+de+se+comunicar+ pelo+celular.aspx>. Acesso em: 13 jun. 2014.

KALVERKÄMPER, H. Die Symbiose von Text und Bild in den Wissenchaften. In: TITZMANN, M. (Org.). Zeichen (theorie) und Praxis. Passau: Rothe, 1993. p. 199-226.

KRESS, G.; LEEUWEN, T. Reading Imagens: The Grammar of visual design. Londres: Routledge, 1996.

Visual and verbal modes representation in electronically mediated communication: the potentials of new forms of text. In: SNYDER, I. (Ed.). Page to Screen: Taking Literacy Into the Electronic Era. London: Routledge, 1998. p. 53-79.

Discurso multimodal. Los modos y los medios de la comunicación contemporánea. Trad. de Laura Molina, L. FBA, UNLP, 2011, p. 1-14.

MARCUSCHI, L. A. Gêneros Textuais Emergentes no Contexto da Tecnologia Digital. In:__ XAVIER, A. C. Hipertexto e Gêneros Digitais: novas formas de construção de sentido. Rio de Janeiro: Editora Lucerna, 2010. p. 13-67.

MARTINEC, R; SALWAY, A. A system for image-text relations in new (and old) media. Visual Communication. London: SAGE publications, v. 4 , n. 3, p. 339-374, 2005. Disponível em: $<$ http://vcj.sagepub.com/10.1177/14703572050 55928>. Acesso em: 13 jun. 2014. 
MCNEILL, D. (Ed.). Language and Gesture.

Cambridge: CUP, 2000.

SANTAELLA, L; NÖTH, W. Imagem, cognição, semiótica, mídia. São Paulo: Iluminuras, 1997.

XAVIER, A. C. A Era do Hipertexto: Linguagem \& Tecnologia. Recife: Ed. Universitária da UFPE, 2009.

. Letramento digital e ensino. In:

Alfabetização e Letramento. CEEL, 2005. 